\title{
O mercado de trabalho para idosos: a consultoria como possibilidade de atuação.
}

\author{
Lygia Zaia Morato ${ }^{1, *}$, Heloísa Gonçalves Ferreira²
}

${ }^{1}$ http://orcid.org/0000-0002-3545-9378 / Universidade Federal do Triângulo Mineiro (UFTM), Brasil

2 http:/ /orcid.org/0000-0002-1663-2534 / Universidade do Estado do Rio de Janeiro (UERJ), Brasil

Prestar serviços de consultoria em empresas pode ser uma alternativa para idosos que desejam permanecer ativos no mercado de trabalho. Este estudo qualitativo e exploratório tem por objetivo compreender certas percepções e atitudes atribuídas pelo idoso em seu processo laboral como consultor em empresas. Participaram desta investigação oito idosos consultores que atuavam em empresas de grande porte, selecionados por meio da técnica metodológica qualitativa intitulada "bola-de-neve". Foi elaborado e aplicado um roteiro de entrevista semi-estruturada. Os resultados foram analisados a partir da análise temática e interpretados por teorias psicológicas a partir da percepção de desenvolvimento do idoso. Evidencia-se que muitos idosos permanecem trabalhando por se identificarem com a atividade e levarem em consideração as motivações financeiras para seguir na atuação laboral. A consultoria apresenta desafios como qualquer profissão, sendo uma opção viável para alguns idosos se manterem no mercado de trabalho. No entanto, este cargo só está disponível para uma parcela específica de idosos. Outras opções de inserção no mercado de trabalho e seus impactos no bem estar precisam ainda ser investigadas.

Palavras-chave: aspirações profissionais, envelhecimento, atitudes profissionais.

\section{The labor market for the elderly: possibilities to work as a consultant}

Abstract

Providing consulting services in companies can be an alternative for seniors who wish to remain active in the job market. This qualitative and exploratory study aimed to understand elderly people's perceptions and attitudes regarding their work as a consultant in enterprises. Participants were composed of eight elderly people who worked as consultants in large companies, selected for the study through the "snowball" technique. A semi-structured interview script was elaborated and applied. The results were analyzed according to thematic analysis and interpreted by psychological theories of elderly development. Older people remain working due to self identification with the activity and financial motivations. Working as a consultant brings challenges like any other job, but is a feasible option for some seniors who want to stay in the labor market. However, this position is not available for all elderly people. Other options of remaining in the labor market and their impacts on well-being still need to be investigated.

Keywords: professional aspirations, aging, professional attitude.

\section{E1 mercado laboral para las personas mayores: la consultoría como posibilidad de actuación}

Resumen

Proporcionar servicios de consultoría en las empresas puede ser una alternativa para las personas mayores que desean mantenerse activas en el mercado laboral. Este estudio cualitativo y exploratorio tiene como objetivo comprender ciertas percepciones y actitudes atribuidas por los adultos mayores en sus procesos laborales como consultor en empresas. Participaran de esta investigación ocho consultores mayores que trabajaban en grandes empresas, seleccionados por medio de la técnica metodológica intitulada "bola de nieve". Fue elaborado y aplicado un guión de entrevista semiestructurada. Los resultados fueron analizados a partir del análisis temático e interpretado por teorías psicológicas a través de la percepción del desarrollo de los ancianos. Es evidente que muchas personas mayores siguen trabajando debido a la identificación que tienen con las actividades involucradas en sus trabajos y llevaren en consideración las motivaciones financieras. La consultoría presenta desafíos como cualquier profesión y es una opción viable para algunos adultos mayores para permanecer en el mercado laboral. Sin embargo, esta posición solo está disponible para una parte específica de los ancianos. Todavía hay que investigar otras opciones de inserción en el mercado de trabajo y sus impactos en el bien estar de trabajador.

Palabras-clave: aspiraciones profesionales, envejecimiento, actitudes profesionales. 
Mundialmente vem ocorrendo um processo de envelhecimento da população e o Brasil está incluído neste cenário de expansão (Miranda, Mendes, \& Silva, 2016). Antes de apresentarmos dados que comprovem este crescimento, é necessário estabelecer parâmetros para identificar pessoas idosas, ressaltando que existem divergências na classificação etária para a categoria em países desenvolvidos e países em desenvolvimento (Brasil, 2017). Portanto, nesta pesquisa adotamos o que determina o Estatuto do Idoso no Brasil (Lei ${ }^{\circ} 10.741$, de $1^{\circ}$ de outubro de 2003), considerando idoso todo indivíduo com idade igual ou superior a sessenta anos (Brasil, 2017).

Segundo pesquisas realizadas pelo Instituto Brasileiro de Estatística e Geografia (IBGE), no ano de 2000, a população acima de 60 anos era formada por 9.935 .100 pessoas. Em 2015, aproximadamente 25 milhões de pessoas tinham idade igual ou maior a 60 anos e estimativas apontam que o país terá mais de 30 milhões de idosos em 2020 (IBGE, 2013). Dessa forma é possível afirmar que, segundo o IBGE, a população brasileira está efetivamente envelhecendo.

O processo de envelhecimento está relacionado à vida de todos os seres vivos e também à espécie humana, estando atrelado às condições de vida e de trabalho do indivíduo, envolvendo uma série de alterações biológicas e sociais que ocorrem de maneira singular para cada sujeito (Camarano \& Kanso, 2016). Entretanto, o fenômeno do envelhecimento populacional é um fato novo para a sociedade, trazendo consigo mudanças nos diversos âmbitos, como o social, cultural, econômico e político (Miranda et al., 2016). Surge, desta forma, a necessidade de novos estudos que se dediquem ao tema e à criação de novas políticas públicas e programas sociais que incluam os idosos e suas formas singulares de viver esta fase da vida (Carvalho, Paiva \& Carvalho, 2017).

O grupo de indivíduos que compõem a denominada terceira idade pode ser considerado heterogêneo (Camarano \& Kanso, 2016). Uma parcela dessa população encontra-se em plenas condições físicas, psicológicas e inseridas em atividades sociais e ocupacionais muitas vezes informalmente. Nessa parcela, existem pessoas que possuem o desejo de permanecer atuantes no mercado de trabalho, seja porque não conseguiram ainda se aposentar, ou mesmo após aposentados, para a complementação de renda e/ ou como forma de se manterem ocupados (Felix, 2016). Outro motivo que deve ser considerado para a permanência de idosos no mercado de trabalho é que o trabalho em nossa sociedade é visto como atividade importante na construção da identidade social e lhes permite uma noção de pertencimento (Rovida, 2016).

Como forma de assegurar a permanência e os direitos do idoso no mercado de trabalho, o Estatuto do Idoso redigiu artigos, especificamente o artigo $26^{\circ}$, que determina que "o idoso tem direito ao exercício de atividade profissional, respeitadas suas condições físicas, intelectuais e psíquicas", e os artigos $27^{\circ}$ e o $28^{\circ}$ da referida lei, visando garantir ao idoso a possibilidade de continuidade no mercado de trabalho (Brasil, 2003). Contudo, esses direitos apresentam-se ainda desconhecidos para muitas pessoas, até mesmo para os próprios idosos (Martins \& Massarollo, 2010).

Quanto ao mercado de trabalho, além de apresentar dificuldades em incluir indivíduos com idade mais avançada, quando o fazem, dispõem de condições desfavoráveis de empregabilidade como remunerações mais baixas e maiores chances de demissão, se comparado aos indivíduos mais jovens (P. C. C. Ribeiro, Almada, Souto \& Lourenço, 2018). Felix (2016) pontua que uma das razões para a dificuldade de os profissionais mais maduros permanecerem empregados deve-se aos tempos de crise, constante necessidade de aprendizagem e consequente obsolescência e desvalorização das capacidades e experiências acumuladas. Outra justificativa para que isto ocorra deve-se à compreensão de que pessoas mais jovens são tidas como mais ágeis, produtivas, flexíveis e habituadas a tecnologias, contribuindo para desvalorizar o idoso e colaborando para que ele próprio acredite estar em uma fase inútil, julgando-se incapaz, improdutivo e obsoleto (Felix, 2016).

De acordo com P. C. C. Ribeiro et al. (2018), fatores como qualificação e maior escolaridade oferecem as melhores chances para indivíduos permanecerem ativos no mercado de trabalho, sendo essas características de idosos que atuam no contexto empresarial. Vanzella, Lima-Neto e Silva (2011) ressaltam a importância de que os idosos que trabalham neste contexto tenham a oportunidade de exercitar gestões mais participativas e não apenas focar-se em execuções de tarefas, de forma a possibilitar que seus conhecimentos, experiências e atributos intelectuais auxiliem na transformação e amadurecimento das organizações. Essa ideia de produtividade na etapa da velhice está em consonância com os pressupostos da Teoria Psicossocial do Desenvolvimento de Erik Erikson, que assume que a etapa desenvolvimental caracterizada pela crise da geratividade vs. estagnação pode ser enfrentada pelas pessoas de meia idade através de tarefas evolutivas como transmissão de conhecimento, ideias e valores à geração seguinte (Erikson, 1998). Nessa direção, uma possibilidade de inserção, reinserção e manutenção de profissionais idosos no mercado de trabalho é a consultoria para as empresas.

O termo consultoria empresarial surgiu por volta de 1850 , quando houve o aumento e complexidade das organizações industriais (Donadone, Silveira \& Ralio, 2012). Este cargo ganhou notoriedade nos Estados Unidos, especificamente em 1930, depois da quebra da bolsa de Nova York, quando o mercado sentiu a necessidade em precaver-se contra futuras crises, buscando aconselhamento nas áreas financeiras, estratégicas e organizacional (Donadone et al., 2012). No Brasil, essa forma de atuar evoluiu a partir da década de 60 , devido ao crescimento do polo industrial e pela necessidade que surge em consequência desta nova dinâmica de trabalho (Caliari \& Scherer, 2017).

Existem na literatura diversas definições sobre a consultoria. Este fenômeno deve-se ao fato singular de que a consultoria é um campo de atuação multiprofissional e acaba por apresentar quase todo o seu campo conceitual transposto por várias áreas disciplinares (Gonçalves \& Vasconcellos, 1991). Dessa forma, diversas visões diferentes devem ser consideradas. Por exemplo, os autores Silva Júnior, Santos, Feitosa e Vidal (2012) definem a consultoria como um serviço realizado por pessoas qualificadas em suas respectivas áreas de atuação, que tem como objetivo oferecer soluções e opções de mudanças à organização contratante. Silva (2013) compreende a atividade do consultor como uma forma de trabalho que tem por objetivos dar respostas às exigências organizacionais frente ao cenário econômico complexo e diante das mudanças na organização e gestão do trabalho. Caliari e Scherer (2017) definem a consultoria como serviço que pode promover redução de custos combinado a inovação.

A consultoria pode ser exercida em duas formas mais comuns: a consultoria interna, que é aquela em que o consultor se dedica totalmente a uma organização, considerado um funcionário da mesma, e a consultoria externa que é aquela na qual o profissional presta serviços ocasionais às organizações, atuando como um profissional autônomo (Caliari \& Scherer, 2017). Normalmente, esta é uma atividade profissional que pode ser exercida de forma flexível, em termos de carga horária (Azevedo, Tonelli \& Silva, 2015) e pode ser prestada por qualquer profissional, de diferentes áreas do conhecimento, em função de sua expertise específica.

Portanto, considerando que o número de idosos brasileiros está aumentando gradativamente (IBGE, 2013), que existem benefícios na manutenção de uma atividade laboral (Rovida, 2016) e que a consultoria aparece como uma opção ocupacional onde o idoso pode manter-se ativo no mercado de trabalho exercendo funções importantes para as organizações a partir de suas experiências e 
qualificações (Vanzella et al., 2011), é relevante investigar as percepções e vivências de idosos em relação à consultoria enquanto uma opção de trabalho. Desta forma, este estudo teve por objetivo conhecer as motivações, sentimentos e atitudes de idosos sobre o seu trabalho como consultor e seus possíveis impactos no bem-estar.

\section{Método}

Trata-se de um estudo qualitativo, transversal, de caráter exploratório.

\section{Participantes}

Para esta pesquisa foram convidados oito idosos, utilizando o critério do Estatuto do Idoso no Brasil (Lei n ${ }^{\circ} 10.741$, de $1^{\circ}$ de outubro de 2003), que reconhece todo indivíduo com idade igual ou superior a 60 anos como idoso (Brasil, 2017), que estivessem ativos no mercado de trabalho e prestando serviços de consultoria para empresas de grande porte no Estado de São Paulo. Não houve restrição com relação ao sexo, tempo de atuação como consultor, nível de instrução, classificação econômica e ramo de atuação na empresa. Optou-se por limitar a pesquisa para empresas de grande porte, utilizando a definição do Serviço Brasileiro de Apoio às Micro e Pequenas Empresas - SEBRAE (2010), que considera grandes empresas aquelas que possuem mais de 500 colaboradores no setor industrial e mais de 100 colaboradores no setor comércio e serviços. A inclusão deste critério se justifica pelo fato de que instituições com características de possuir um número elevado de colaboradores e maior capacidade de produção foram pioneiras na contratação de pessoas idosas na categoria de consultores no contexto brasileiro (Donadone et al., 2012). O motivo de incluir a limitação geográfica justifica-se pela escolha em realizar a entrevista face a face.

Os indivíduos que participaram da pesquisa foram recrutados por meio da técnica bola de neve. Nessa técnica, o entrevistador estabelece contato inicial com alguns sujeitos, previamente identificados como membros do grupo que se pretende estudar, e esses sujeitos indicam ou põem o investigador em contato com outros membros desse grupo e assim sucessivamente (Costa, 2018). Nesta pesquisa, o primeiro indivíduo foi identificado por meio da rede social de negócios Linkedin, que além de aceitar participar da pesquisa, colaborou com indicações de outros profissionais que cumpriam com os critérios de inclusão da pesquisa.

\section{Instrumentos}

Foi utilizado um roteiro de entrevista semiestruturado, previamente elaborado pelas autoras, abarcando perguntas principais que foram complementadas por outras questões inerentes às circunstâncias momentâneas à entrevista (Manzini, 2012). As perguntas foram formuladas para investigar percepções e atitudes do participante em relação ao seu trabalho como consultor. Foram elaboradas perguntas para coleta de dados sociodemográficos e questões para conhecer as motivações pela permanência no mercado de trabalho, os significados, sentimentos, experiências, expectativas, dificuldades e desafios vivenciados na atividade profissional. Também foram elaboradas perguntas para conhecer a história pessoal e profissional desses sujeitos.

\section{Procedimentos de Coleta de Dados e Cuidados Éticos}

Em contato inicial com os participantes via telefone, as entrevistas foram agendadas e antes de sua realização, foi solicitado aos participantes que lessem e assinassem o Termo de Consenti- mento Livre e Esclarecido em atenção às disposições éticas em pesquisas com seres humanos. Os participantes foram entrevistados individualmente, face a face. As entrevistas tiveram duração de aproximadamente uma hora e meia cada, foram audiogravadas mediante a autorização dos entrevistados e realizadas segundo a disponibilidade de cada participante em local reservado, uma sala livre de interferências externas. As entrevistas foram transcritas na íntegra e literalmente para posterior análise e composição dos eixos temáticos. Para garantir o sigilo dos voluntários, os participantes foram identificados por meio de números.

Em relação às exigências éticas para as pesquisas envolvendo seres humanos, o desenvolvimento deste estudo está amparado nas resoluções $n^{\circ} 466$, de 12/12/2012 e $n^{\circ}$ 510, de 07/04/2016. Esta pesquisa foi aprovada pelo Comitê de Ética em Pesquisa da Universidade Federal do Triângulo Mineiro com CAAE 69053017.5.0000.5154 em 14/07/2017.

\section{Procedimentos de Análise de Dados}

Os resultados foram analisados por meio da análise de conteúdo temática de Braun e Clarke, que compreende um método que identifica, analisa e relata padrões (temas) dentro dos dados, possibilitando a interpretação de vários aspectos do tema da pesquisa (Braun \& Clarke, 2006). A análise temática possui como característica marcante a flexibilidade, por isso, pode ser dividida em diversas opções analíticas (Braun \& Clarke, 2006).

Para esta pesquisa, adotou-se o método essencialista \realista, entendido como aquele que relata as experiências, significados e realidades dos participantes. Os eixos temáticos foram identificados de forma indutiva, o que significa que os temas identificados estão fortemente ligados aos próprios dados e possuem abordagem semântica, que envolve uma progressão, desde a descrição dos dados, até a interpretação (Braun \& Clarke, 2006).

Como referencial teórico para este estudo, foram utilizados teorias psicológicas do desenvolvimento do idoso, tais como a Teoria do Desenvolvimento Psicossocial de Erik Erikson, que postula o desenvolvimento humano em oito estágios ou ciclos psicossociais. Cada estágio ou ciclo é caracterizado pela emergência de um tema ou crise evolutiva e enfrentamento ativo dessa crise. Nesse trabalho analisamos em especial o estágio denominado maturidade, que possui como crise dominante a Geratividade vs. Estagnação (Erikson, 1998). Os resultados também foram interpretados a partir da Teoria da Seleção, Otimização e Compensação (SOC) de Paul Baltes (1997), que postula que o envelhecimento bem-sucedido depende da capacidade do indivíduo se reorganizar e se adaptar a partir das perdas psicossociais trazidas com o processo de envelhecer. Além dos referenciais teóricos adotados, os resultados também foram analisados à luz da literatura nacional sobre áreas de mercado de trabalho, mercado de trabalho para idosos, aposentadoria e consultoria.

\section{Resultados e Discussão}

Os principais dados demográficos dos participantes podem ser visualizados na Tabela 1. Embora o sexo não tenha sido elencado como um critério de seleção dos participantes nota-se que todos os participantes eram do sexo masculino neste estudo. Importante ressaltar que este resultado pode dever-se ao fato da utilização da técnica bola-de-neve como forma de recrutamento dos participantes, uma vez que os participantes tendem a indicar outras pessoas com características semelhantes a sua, que é um viés a ser considerado.

Ao longo de todo o ciclo da vida, homens e mulheres apresentam comportamentos distintos frente ao mercado de trabalho (Leandro-França et al., 2015), chegando à velhice com atividades 
Tabela 1

Caracterização do perfil dos participantes

\begin{tabular}{|c|c|c|c|c|c|c|}
\hline Participante & Idade & Sexo & Formação & $\begin{array}{l}\text { Tempo de atua- } \\
\text { ção (anos) }\end{array}$ & $\begin{array}{l}\text { Tipo de consul- } \\
\text { toria }\end{array}$ & Aposentado \\
\hline 1 & 69 & M & Advogado & 20 & Externa & $\operatorname{Sim}$ \\
\hline 2 & 69 & M & Administração \Marketing & 1 & Interna & Sim \\
\hline 3 & 64 & M & Advogado \Eng.Químico & 15 & Interna & Sim \\
\hline 4 & 67 & M & Economista $\backslash$ Eng. Civil & 25 & Externa & Sim \\
\hline 5 & 61 & M & Economista & 10 & Externa & $\operatorname{Sim}$ \\
\hline 6 & 79 & M & Administrador & 20 & Interna & Sim \\
\hline 7 & 61 & M & Eng. Mecânico & 10 & Interna & $\operatorname{Sim}$ \\
\hline 8 & 67 & M & Psicólogo & 23 & Externa & Sim \\
\hline
\end{tabular}

diferenciadas. O fato de todos os participantes deste estudo serem homens pode levantar a hipótese de que em comparação às mulheres idosas, há uma predominância de homens idosos no mercado de trabalho, mais especificamente no contexto empresarial. De fato, há dados que apontam para uma taxa de participação na força de trabalho mais elevada entre homens do que mulheres, quando considerada apenas a população idosa que está inserida no mercado de trabalho brasileiro (Kreling, 2016). No entanto, a natureza qualitativa do presente estudo não permite realizar generalizações, mas apenas apontar semelhanças dos dados observados neste estudo com outras pesquisas que versam sobre características sociodemográficas de idosos brasileiros inseridos no mercado de trabalho.

Sobre a idade dos participantes, notou-se que a maioria era idosos jovens, ou seja, com idade entre 60 e 70 anos, havendo apenas um participante com mais de 70 anos. A escolaridade de todos os participantes foi superior completo, sendo que três deles possuíam ainda uma segunda graduação, ou seja, os participantes desse estudo eram altamente escolarizados. Esse perfil observado está em conformidade com estudos que demonstram que as oportunidades de trabalho para idosos são mais elevadas para aqueles com formação superior (P. C. C. Ribeiro et al., 2018) e que idosos que se mantém no mercado de trabalho são mais qualificados do que idosos inativos profissionalmente (Kreling, 2016).

A maioria dos participantes atuava como consultor por pelo menos uma década (com exceção de um participante que iniciou esta carreira recentemente), além de todos serem aposentados. Sobre o tipo de consultoria prestada, observa-se que quatro participantes prestavam consultoria externa, isto é, de forma autônoma, e quatro participantes prestavam consultoria interna, isto é, eram funcionários de uma empresa. Esses dados podem sugerir que a consultoria é uma opção flexível de permanência no mercado de trabalho para idosos que mantém ou não vínculo empregatício com a empresa.

Seguindo as diretrizes fornecidas por Braun e Clarke (2006) para categorizar e analisar qualitativamente os dados encontrados a partir das entrevistas, as escolhas dos eixos temáticos foram feitas não só a partir da frequência dos dados, mas também fazendo o exercício de capturar algo importante em relação à questão global da investigação. O eixo comum dos discursos constitui a consultoria como uma possibilidade de atuação. Derivado desse eixo principal, outros quatro eixos temáticos também foram identificados e serão descritos e discutidos a seguir: (1) as motivações pela permanência no mercado de trabalho; (2) o significado da consultoria na visão dos consultores; (3) os benefícios em atuar como consultor; e (4) as dificuldades em ser um consultor idoso.

\section{Por que permanecer no Mercado de Trabalho como Consultor?}

A história pessoal e profissional de cada sujeito é uma importante aliada para compreender os motivos pela permanência no mercado de trabalho. Durante as entrevistas, puderam ser identificadas experiências que foram compartilhadas pela maioria dos participantes e que os motivaram a buscar novos caminhos para permanecer trabalhando. Logo no início das entrevistas, notou-se uma tendência dos participantes em começar seus relatos falando do período da infância, primeiras conquistas na adolescência, sendo enfatizado, já neste período, o início da trajetória profissional e identificação em produzir algo.

Segundo Rovida (2016), é por meio do trabalho que o indivíduo reconfigura a percepção de si e do seu ambiente, o que possibilita crescimento e desenvolvimento pessoal. Dubar (2012) considera que para esses indivíduos, que se identificam com suas atividades profissionais, a definição de si e a forma como se apresentam a alguém ocorrem invariavelmente em função da empresa ou da profissão exercida. Além disso, trabalhar para estas pessoas pode ser considerado sinônimo de qualidade de vida e saúde mental (L. A. Ribeiro \& Santana, 2015). Nas falas a seguir observa-se como o trabalho pode ser uma dimensão importante da identidade das pessoas:

A consultoria para mim foi a forma que encontrei de permanecer fazendo aquilo que me dá prazer, depois que fui dispensado das minhas atividades. A consultoria tornou minha inspiração, fonte de conhecimento, possibilidade de ajudar pessoas empreendedoras e seus negócios a crescerem, e também me ajudar financeiramente, eu tenho filhos que ainda estudam e precisam da minha ajuda. (Participante 4).

Eu já havia feito um planejamento antes mesmo de aposentar, pois tinha consciência que iria precisar complementar a renda, já que a minha aposentadoria é muito pequena. Comecei a atuar como consultor antes mesmo de me aposentar, e depois da aposentadoria fiquei só com esta atividade. Gosto muito do que faço e tenho muita disposição para o trabalho. Não consigo ficar parado. (Participante 8).

É possível identificar nas falas dos participantes que o ato de trabalhar, além de ser considerado um evento prazeroso e que se relaciona à construção da identidade, também tem repercussões financeiras relevantes, como previsto por P. C. C. Ribeiro et al. (2018). Fontoura et al. (2015) afirmam em sua pesquisa que a população idosa se declara preocupada com a situação financeira após a aposentadoria, em decorrência da perda de salário e benefícios adquiridos. Além da perda do poder aquisitivo, a necessidade de prover a família também é fator que leva os idosos a permanecerem trabalhando (Felix, 2016). Esses dois fatores são exemplificados nas falas do participante 4 e 8 e estão em consonância com estudos que apontam que idosos brasileiros apresentam uma importante função no suporte financeiro a suas famílias, sendo muito deles ainda considerados os chefes da família, por apresentarem a função de provedor da casa (P. C. C. Ribeiro et al., 2018).

Outro ponto relevante a ser discutido refere-se à opção de 
retornar ao trabalho após a aposentadoria para além dos motivos financeiros, que diz respeito à identificação com o trabalho e saúde mental. Antunes et al. (2015) explicam que a aposentadoria, além de um direito previdenciário, se configura como um dos principais eventos críticos da vida adulta, abrangendo diversos processos psicológicos e sociais. Um dos conflitos que acontecem nesse período pode ser caracterizado pela dualidade crise versus liberdade. Assim, por um lado, a aposentadoria é vivenciada com tensão e dificuldade de adaptação ao novo momento e, por outro lado, pode ser sinônimo de liberdade e potencialização das fontes de satisfação devido ao maior tempo livre após o desligamento do trabalho (Antunes et al., 2015). Estudos realizados por França (2014) demonstraram que os aspectos que demarcam esse conflito estão interligados à história de vida do indivíduo, permeada pelo modo como construiu sua identidade, suas relações familiares, de amizade, de trabalho e sua trajetória profissional.

A Teoria Psicossocial do Desenvolvimento de Erik Erikson (1998) também postula que o indivíduo passa por crises psicossociais ao longo da vida, e que o enfrentamento adequado dessas crises pode levar o indivíduo a desenvolver virtudes. Os indivíduos de meia-idade se encontram na etapa da maturidade e dependendo da forma como a crise psicossocial desta fase é enfrentada, o desfecho final pode levar à estagnação ou à geratividade. A partir dos relatos dos participantes acerca dos significados da consultoria, a permanência no mercado de trabalho como consultor apareceu associada à virtude da geratividade, pois os participantes relataram prazer, inspiração, possibilidade de ajudar outras pessoas e desenvolvimento pessoal relacionados à ocupação do cargo de consultor nesta fase da vida.

Para permanecer ativo no mercado de trabalho após a aposentadoria é necessário que se faça a escolha de uma profissão. No processo de escolha são vários os fatores que devem ser considerados, entre eles destacam-se a auto realização, identificação com as atividades da profissão, manutenção de uma vida pessoal equilibrada e finanças (Bartalotti \& Menezes-Filho, 2007). Ao atuar com consultoria, o indivíduo estará em constante relação com pessoas e atuará em ações que envolvem gestão ou aconselhamento (Donadone et al., 2012). Existe a possibilidade de trabalhar com horários e atividades mais flexíveis, dependendo do tipo de contratação (Azevedo et al., 2015). Além disso, este trabalho pode oferecer o sentimento de bem-estar, já que o indivíduo se sente como participante da sociedade (Rovida, 2016). Os participantes desta pesquisa relataram que as principais motivações para atuar como consultores após a aposentadoria foram a possibilidade de se relacionar com outras pessoas de diferentes faixas etárias, a oportunidade de entrar em contato com diversas ideias, a identificação com o trabalho de gestão, o uso da experiência , além da possibilidade de sempre poder aprender mais. Ou seja, as percepções dos participantes acerca da consultoria como oportunidade de transmissão de conhecimento e valores à geração seguinte por meio da otimização de recursos e produção de resultados que mantenham o idoso ativo e contribuindo para a sociedade, corroboram os pressupostos da Teoria de Erikson sobre o desenvolvimento da virtude da geratividade na fase da maturidade (Erikson, 1998).

Gosto de trabalhar com pessoas e passei minha vida profissional inteira lidando com gente e em cargos de gestão, eu me identifico com isso e me sinto realizado atuando nesta atividade. Sempre busco por novos conhecimentos. É uma atualização constante. Os desafios são constantes. A possibilidade de conviver em vários lugares e pessoas diferentes é algo que me satisfaz demais.(Participante 6).
Eu sinto um prazer imenso em ensinar para quem tem interesse em aprender e gosto também da rotina que acontece dentro de empresas. Lá além de ter a possibilidade de compartilhar meus conhecimentos, eu entro em contato com as ideias de outros profissionais e aprendo com eles. Acho isso fantástico! (Participante 3).

Outro motivo exemplificado pelos participantes em escolher este cargo é a preocupação em ajudar trabalhadores mais jovens, que também vivenciam dificuldades para inserir-se no mercado de trabalho (Santos \& Gimenez, 2015). Além disso, alguns consultores levaram em consideração a característica de flexibilidade que a consultoria permite ter, possibilitando realizar outras atividades rotineiras (Azevedo et al., 2015). Esses dois fatores são exemplificados na fala deste participante.

Resolvi depois de um tempo atuar como consultor. Essa decisão foi pensada nos meus filhos, estão tudo formado e com dificuldade em arranjar trabalho. Eu saí de um cargo que tinha uma carga horária e responsabilidade bem mais pesada e virei consultor da minha empresa. Foi a melhor coisa que eu fiz! Eu me sinto bem porque estou trabalhando e porque dei a oportunidade de outra pessoa trabalhar e crescer profissionalmente. Hoje quem tá no meu antigo cargo é um carinha de 33 anos. Continuo ajudando, converso bastante com ele, a gente tem uma relação bem boa. Além disso, hoje em dia eu tenho tempo para fazer outras tarefas que me dão muito prazer, tipo brincar com os meus netinhos, ajudar minha esposa lá em casa e cuidar da horta. (Participante 1).

\section{Qual o Significado da Consultoria para os Idosos?}

A partir das falas dos participantes foi possível identificar uma sintonia com relação à compreensão do que é a consultoria e seus principais significados para os idosos. De maneira geral a atividade é percebida pelos participantes como sendo uma relação de ajuda entre os trabalhadores, uma troca de experiências, saberes que tem como produto final ações de melhorias. Cinco dos participantes pontuaram que a consultoria é uma profissão em ampla expansão e com possibilidades de crescimento corroborando com os resultados da pesquisa de Donadone et al. (2012).

Consultoria, é como se você fosse um professor. Enquanto professor, você professa aquilo que sabe e transmite à quem quer aprender, a experiência adquirida e o conhecimento amealhado, você ajuda o outro, pode clarificar algum assunto. Consultoria é ensinar o que já vivenciamos, só que em um lugar que não é a sala de aula. (Participante 3).

A consultoria na sua essência é uma relação de ajuda em seu mais alto valor, pela forma de intervenção, na qual prioriza o diálogo, valoriza seus conhecimentos adquiridos ao longo de tantos anos de dedicação e ressalta princípios éticos que norteiam cada contato e cada momento de interação com o cliente. Percebo que é uma profissão que está em expansão. (Participante 7).

A consultoria é o processo de você conhecer a empresa, o cliente, suas potencialidades e necessidade. É o processo de você ofertar para todos os envolvidos melhorias, através do seu conhecimento e de suas atualizações constantes na sua área profissional. (Participante 2). 
Todas essas definições confirmam os conceitos utilizados por Silva Júnior et al. (2012), Silva (2013) e Caliari e Scherer (2017) que remetem a consultoria a um trabalho de aconselhamento para organizações, nos quais profissionais qualificados apresentam melhorias, soluções e inovações, afetando todos os envolvidos de alguma forma. Também é possível observar novamente que a virtude da geratividade postulada na teoria de Erikson (1998) aparece no relato dos participantes que declaram significar sua atuação profissional como sinônimo de ajudar, ensinar e transmitir conhecimento à próxima geração. A geratividade foi definida por Erikson (1998) como a preocupação com o desenvolvimento e bem-estar das próximas gerações. Os relatos dos participantes mostram que os mesmos percebem a consultoria como uma oportunidade significativa de contribuir para o desenvolvimento das organizações e das gerações seguintes.

Um ponto relevante que merece destaque na fala dos participantes é sobre a necessidade constante de se atualizar. Murad (2017) pontua que para se inserir e manter-se no mercado de trabalho, é necessário que o processo de formação e qualificação seja contínuo, exigindo melhorias constantes do indivíduo. Ser consultor envolve uma realidade que está em constante movimento e avanço (Donadone et al., 2012). Ter o comprometimento em atualizar-se é a premissa básica para manter-se ativo no mercado de trabalho (Murad, 2017) nesta categoria profissional. As falas destes dois participantes exemplificam bem a necessidade de se atualizar.

O mercado é muito competitivo. Todo o dia surge algo novo ou atualizam algum assunto. Veja bem se eu não acompanhar essas mudanças eu me torno obsoleto. Tornando-se obsoleto os clientes não vão mais ter interesse no meu trabalho e consequentemente eu serei muito prejudicado. (Participante 1).

Se não tiver o cuidado em investir no meu próprio conhecimento, acredito que além de me queimar como profissional posso trazer um prejuízo incalculável para a empresa. (Participante 3).

Ainda com relação ao entendimento de consultoria, neste trabalho tivemos contato com os dois tipos de consultores, com vínculos empregatícios distintos: consultoria interna e consultoria externa. Nas falas a seguir os participantes expressam suas percepções a respeito desses dois tipos de vínculos empregatícios:

Entendo que fazemos a mesma atividade, que é oferecer suporte, aconselhar através dos nossos conhecimentos e experiências de vida, a diferença está na rotina, por exemplo, um consultor interno irá trabalhar como um empregado qualquer e cumprir horas, o consultor externo irá ter maior flexibilidade nisso, escolhendo que dia ele vai trabalhar. Imagino também que o vínculo que você tem com os funcionários seja maior quando você é consultor interno porque você convive diariamente com eles. No processo de escolha sobre qual vínculo atuar, primeiro de tudo pensei qual é o meu interesse? No meu caso eu desejava ter uma vida estável, gosto de ter uma rotina organizada e trabalhar com as mesmas pessoas. Assim, acredito que o meu perfil se encaixe melhor ao de um consultor interno. (Participante 2).

Por ser consultor externo, eu não tenho uma rotina pré-definida. Eu organizo minha agenda e escolho os dias que irei trabalhar. Normalmente eu trabalho os cinco dias da semana e reservo um dia para visitar cada empresa-cliente. Essa forma de atuação dá mais liberdade e este ponto foi primordial no processo de escolha, porque assim, se eu tiver afim de viajar com a minha família eu posso, é só não marcar nenhum compromisso. (Participante 5).

A compreensão com relação às significações entre as consultorias confirma os resultados de pesquisa realizado Caliari e Scherer (2017), que explicam que o consultor externo é uma pessoa autônoma ou funcionário de uma empresa de consultoria contratada para prestar serviços em organizações-clientes, na área que possua experiência e habilidade, enquanto o consultor interno faz parte do quadro de funcionários da empresa, ocupando normalmente o cargo de técnico ou gestor. $\mathrm{Na}$ fala do participante 2, é possível analisar como ele percebe cada tipo de consultoria, atribuindo à consultoria interna característica de algo mais rígido e para a consultoria externa uma atividade mais flexível e livre. Com relação ao processo de escolha entre as duas, observa-se que os dois participantes consideraram as vantagens e desvantagens dos vínculos, escolhendo aquela que acredita se encaixar melhor ao seu perfil.

A Teoria de Seleção Otimização e Compensação (SOC) postulada por Baltes (1997) também oferece suporte para interpretação dos relatos sobre o significado da consultoria para idosos. De acordo com a SOC, conforme o indivíduo envelhece ocorrem perdas biológicas e psicossociais, havendo necessidade do idoso buscar recursos de adaptação frente a essas perdas. Logo, perdas de resistência física, cognitivas e funcionais podem ocorrer e por estas razões o idoso pode ficar menos apto para lidar com rotinas intensas de trabalho. Desta forma, a consultoria pode surgir como uma estratégia para otimizar os recursos que o idoso ainda dispõe para exercer suas atividades laborais, uma vez que a consultoria traz uma flexibilidade que permite ao idoso selecionar certas metas profissionais e otimizar seus recursos para cumpri-las. Assim o idoso também fica livre para assumir outras atividades, tais como passar mais tempo com a família, que também julga ser importante para esta etapa da vida. Ao selecionar metas e otimizar os recursos existentes, o indivíduo consegue se adaptar melhor à situação e compensar as perdas que venha a enfrentar ao longo do ciclo de vida (Baltes, 1997).

\section{Os Benefícios em Atuar como Consultor}

Levando em consideração que a experiência vivida é única e singular para cada sujeito (Fanton, 2011), nos últimos dois eixos temáticos priorizou-se por trabalhar com as falas consideradas relevantes, isto é, cujo conteúdo estivesse presente nas discussões de pesquisas científicas, mesmo que a frequência dessas falas fosse baixa. Sobre os impactos positivos de trabalhar como consultor, os participantes revelaram que o trabalho gerou alegria, satisfação, qualidade de vida, sentimento de segurança com o futuro, criatividade para produzir novos projetos e harmonia com o corpo e a alma.

Há uns anos atrás eu não iria imaginar que estivesse atuando com consultoria e nem imaginava que iria desenvolver novos projetos com a minha idade. A consultoria além de ter me oferecido uma melhor qualidade de vida, hoje sinto que vivo com mais segurança financeira, me sinto produtivo, útil e em harmonia com meu corpo e minha alma, eu estou bem e muito feliz. (Participante 5).

A consultoria me tirou do fundo do poço praticamente. Eu tinha medo de me aposentar porque associava que não conseguiria mais me sentir útil e isso me gerava ansiedade e muito sofrimento. Meus amigos falam que eu sou outra pessoa e eu também acho que mudei bastante. Evoluímos independente da idade e responsabilizo em grande parte a consultoria por esta evolução. Apren- 
di a aproveitar mais os momentos. (Participante 6).

Com os relatos dos participantes percebe-se que a consultoria proporcionou impactos positivos nas suas vidas, assegurando qualidade de vida, o que, por sua vez, promove saúde mental, equilíbrio psíquico, físico e social, confiança na satisfação das próprias necessidades, motivações para o trabalho, criatividade, vontade de inovar e também noção de pertencimento a nossa sociedade. Os estudos de P. C. C. Ribeiro et al. (2018) consideram $\mathrm{o}$ ato de trabalhar fundamental para a qualidade de vida do sujeito idoso, que deseja permanecer ativo no mercado de trabalho, mesmo após a aposentadoria. Isso se deve ao fato do trabalho representar o papel de regulador da organização humana, motivar o sujeito a participar de todos os âmbitos da vida social, além das atividades exercidas servirem de ponto de referência para as pessoas, sendo maléfico desarticular-se delas nestas situações (Neves et al., 2018). Este mesmo estudo ainda afirma que o trabalho faz o ser humano se sentir útil e numa sociedade utilitarista esse sentimento é muito importante para que cada um reconheça sua finalidade como ser humano (Neves et al., 2018).Neste estudo foi constatado que para este grupo de idosos, isso não é diferente.

\section{As Dificuldades Vivenciadas pelo Idoso no Cargo de Consultor}

Ao questionar sobre os principais desafios vivenciados neste cargo, os participantes pontuaram que a presença de preconceito por ser idoso, a falta de uma descrição de cargos, o desconforto com alguns colaboradores da empresa e a expectativa por um salário melhor estão presentes na atuação como consultor, demonstrando assim, que as atividades de consultor também implicam em dificuldades e em barreiras a serem superadas como em qualquer profissão.

Olha, já vivenciei muitas situações de preconceito por ser idoso. Preconceito vai estar lá, por ser idoso, por ser mulher, gay, e por aí vai, não vai adiantar você se vitimizar, nesse tipo de situação eu enfrento de cabeça erguida, conheço minhas competências, limites e me atualizo sempre, tô sempre em curso, congresso, e isso acho que é o fator mais importante, sei o que eu tenho a oferecer, sei que o resultado vai ser muito bom. (Participante 5).

Quando fui contratado pela empresa, tive problema com três gestores que se incomodaram muito com a minha presença lá, pois entendiam que iriam perder o poder na tomada de decisão. Para conseguir fazer um trabalho efetivo precisei chamar os três para um bate-papo. Além de fazer seu trabalho é necessário saber ouvir as necessidades dos outros e evitar conflitos.(Participante 7).

Fui o primeiro consultor interno contratado pela empresa. Não tinha uma descrição de cargo e foi bem frustrante no início pois a empresa colocava certa expectativa na minha atuação, mas não me falava o que precisava ser feito e não me dava tanta abertura para conhecê-la. Foi necessário muito diálogo, paciência e vontade de dar certo para as coisas acertarem. (Participante 2)

Eu achava que iria ganhar muito dinheiro, mas não é a realidade. Dependendo dos casos você não terá $13^{\circ}$, vai precisar abrir empresa, pagar contador, enfim, a solução é fazer planejamento orçamentário anual. (Participante 8).
Apesar de apresentarem diversas situações desafiadoras, é possível observar nas falas que os próprios consultores já apresentavam soluções ou estratégias para enfrentá-las. Nota-se que as dificuldade apresentadas estão bastante atreladas ao cargo da consultoria como profissão, resultado que corrobora a pesquisa de Gonçalves e Vasconcellos (1991) e Caliari et al. (2019) que apresentaram em um dos tópicos os principais desafios vivenciados nesta profissão, ressaltando em especial a relação consultor-cliente que às vezes possui como característica a falta de confiança em ambas as partes. Logo, é necessário que o idoso busque desenvolver estratégias de enfrentamento para superação dos desafios inerentes a este cargo.

\section{Conclusão}

O crescimento da população idosa e o aumento da expectativa de vida têm-se tornado, com frequência, temas de discussões em diversos setores da sociedade brasileira (Camarano \& Kanso, 2016). Um desses temas é a inserção do idoso no mercado de trabalho. Sabe-se que existe uma parcela da população brasileira que tem interesse em manter-se ativa no mercado de trabalho, mesmo após a aposentadoria (P. C. C. Ribeiro et al., 2018). Para os próximos anos, é possível afirmar que muito provavelmente este interesse aumentará na mesma proporção que o número de idosos no país. Portanto, investigações a respeito das percepções dos idosos no mercado de trabalho serão cada vez mais necessárias como forma de compreender como idosos têm passado por essa experiência e quais os possíveis impactos de exercer esta profissão na vida dessas pessoas.

Neste estudo, reconheceu-se que os motivos mais recorrentes para permanecer ou voltar ao mercado de trabalho, são a identificação com a atividade laboral, a necessidade de uma renda como um complemento essencial à aposentadoria e a noção de ser sujeito ativo da sociedade. Esses resultados corroboram com os estudos utilizados como referencial teórico da pesquisa, demonstrando que o trabalho é considerado uma referência social para as pessoas e desarticular-se desta atividade, em certos contextos, pode trazer prejuízos (Neves et al., 2018). Além disso, manter-se ativo no mercado de trabalho como consultor parece ser uma estratégia eficaz para o desenvolvimento de virtudes tais como a geratividade na etapa da maturidade (Erikson, 1998), e de adaptação frente a perdas inerentes ao envelhecimento (Baltes, 1997).

De acordo com os resultados apresentados, é possível concluir que a consultoria é uma atividade profissional que pode se encaixar às necessidades e características da população idosa, quando esta conta com qualificação e alta escolarização, gerando impactos no bem-estar, o que por sua vez, contribui para a qualidade de vida no processo de envelhecimento (P. C. C. Ribeiro et al., 2018). Contudo, esta profissão apresenta algumas dificuldades e desafios a serem superados como em qualquer outra profissão, embora seja possível concluir que a consultoria pode ser uma possibilidade de atuação profissional para os idosos. No entanto este cargo só está disponível para uma pequena parcela da população idosa: pessoas mais escolarizadas, qualificadas, com histórico profissional de sucesso e com disponibilidade de emprego na área de consultoria. Outras opções de inserção no mercado de trabalho e seus impactos no bem estar, quando o idoso não conta com tais características, precisam ainda ser investigadas em estudos futuros.

Este estudo limitou-se a apresentar uma categoria específica de trabalho, que por suas características pode ter também limitado o número de participantes no estudo. O uso da técnica bola-de-neve é um viés a ser considerado, pois implica em um grupo homogêneo, uma vez que o participante costuma indicar outros indivíduos com características semelhantes às dele. Logo, os resultados devem ser analisados levando-se em consideração esta limitação do estudo. Recomenda-se que novos estudos sejam realizados a fim 
de incluir pessoas do sexo feminino e também investigar outras categorias de trabalho que atendam a outros perfis de idosos da população idosa brasileira. Desta forma, será possível a investigação de outros contextos de trabalhos para idosos brasileiros, como forma de explorar outros estilos de vida que possam estar associados a uma maior qualidade de vida ao longo do envelhecimento.

\section{Referências}

Antunes, M. H., Soares, D. H. P., \& Silva, N. (2015). Orientação para aposentadoria nas organizações: Histórico, gestão de pessoas e indicadores para uma possível associação com a gestão do conhecimento. Perspectivas em Gestão \& Conhecimento, 5(1), 43-63. Recuperado de https://periodicos.ufpb.br/ojs2/ index.php/pgc/article/view/19114

Azevedo, M. C., Tonelli, M. J., \& Silva. A. L. (2015). Contratos flexíveis de trabalho: diferentes perfis de trabalhadores qualificados brasileiros. Revista de Administração - USP, 50(3), 277-291. https://doi.org/10.5700/rausp1200

Baltes, P.B. (1997). On the incomplete architecture of human ontogeny. Selection, optimization and compensation as foundation of developmental theory. American Psychologist, 52(4), 366-380. https://doi.org/10.1037// $\underline{0003-066 x .52 .4 .366}$

Bartalotti, O., \& Menezes-Filho, N. (2007). A relação entre desempenho da carreira no mercado de trabalho e a escolha profissional dos jovens. Economia aplicada, 11(4), 487-505. https://doi.org/10.1590/S1413-80502007000400002

Batista, E. C., Matos, L. A. L., \& Nascimento, A. B. (2017). A entrevista como técnica de investigação na pesquisa qualitativa. Revista Interdisciplinar Científica Aplicada, 11(3), 23-38. Retirado de https://www.researchgate.net/ profile/Eraldo Batista/publication/331008193 A ENTREVISTA COMO TECNICA DE INVESTIGACAO NA PESQUISA QUALITATIVA/links/5c60dfb0299bf1d14cbb4aef/A-ENTREVISTA-COMO-TECNICA-DE-INVESTIGACAO-NA-PESQUISA-QUALITATIVA.pdf

Brasil (2003). Estatuto do idoso: Lei n. 10.741 de 1 de outubro de 2003. (5a. ed.)., rev. e ampl. - Brasília: Câmara dos Deputados, Edições Câmara, 2017. Recuperado de http://www.planalto.gov.br/ccivil 03/leis/2003/110.741.htm

Braun, V., \& Clarke, V. (2006) Using thematic analysis in psychology. Qualitative Research in Psychology, 3(2), 77-101. https://doi.org/10.1191/ $1478088706 \mathrm{qp} 063 \mathrm{oa}$

Caliari, L., \& Scherer, L. A. (2017). Por que contratar um serviço de consultoria empresarial? Uma visão de consultores e empreendedores. Revistas Espacios, 38(9), 25-41. Recuperado de https://www.revistaespacios.com/a17v38n09/ a17v38n09p25.pdf

Caliari, L., Scherer, L. A., \& Flores, S. A. M. (2019). Fatores de insucesso da relação entre consultores empresariais e empreendedores de micro e pequenas empresas. Gestão \& Regionalidade, 35(103), 161-182. https://doi. org/10.13037/gr.vol35n103.4431

Camarano, A. A., \& Kanso, S. (2016). Envelhecimento da população brasileira: uma contribuição demográfica. Em E. V. Freitas \& L. Py. (Orgs.), Tratado de Geriatria e Gerontologia. (pp.52-65). Rio de Janeiro: Guanabara Koogan.

Carvalho, A. B. C., Paiva, A. A., \& Carvalho, C. M. R. G. (2017). Evidências das políticas públicas em favor da pessoa idosa: conquistas e perspectivas. Em C. M. R. G. de Carvalho, \& L.F. de Araújo (Orgs.), Envelhecimento e Práticas Gerontológicas (pp.149-164). Curitiba: CRV.

Costa, B. R. L. (2018). Bola de neve virtual: o uso das redes sociais no processo de coleta de dados de uma pesquisa científica. Revista Interdisciplinar de Gestão Social, 7(1), 15-37. Recuperado de https://portalseer.ufba.br/index.php/ rigs/article/view/24649

Donadone, J. C., Silveira, F. Z., \& Ralio, V. R. (2012). Consultoria para pequenas e médias empresas: as formas de atuação e configuração no espaço de consultoria brasileiro. Revista Gestão Producão, 19(1), 151-177. Recuperado de http://www.scielo.br/pdf/gp/v19n1/a11v19n1.pdf

Dubar, C. (2012). A Construção de si pela atividade de trabalho a socialização profissional. Caderno de Pesquisa, 42(1), 351-367. https://doi.org/10.1590/ $\underline{\mathrm{S} 0100-15742012000200003 .}$

Erikson, E. H. (1998). O ciclo de vida completo (1 a ed.). Porto Alegre: Artes Médicas.

Fanton, M. (2011). Sujeito, sociedade e linguagem: uma reflexão sobre as bases teóricas da pesquisa com narrativas biográficas. Civitas - Revista de Ciências Sociais, 11(3), 529-543. https://doi.org/10.15448/1984-7289.2011.3.10064

Felix, J. (2016). O idoso e o mercado de trabalho. Em A. O. Alcântara, A. A. Camarano, \& K. C. Giacomin, Política Nacional do Idoso: velhas e novas questões. Rio de Janeiro: IPEA. Recuperado de http://repositorio.ipea.gov.br/bitstream/11058/9092/1/O\%20Idoso\%20e\%20o\%20mercado.pdf

Fontoura. D. S., Doll, J., \& Oliveira, S. N. (2015). O desafio de aposentar-se no mundo contemporâneo. Educação \& Realidade, 40(1), 53-79. https://doi. org $/ 10.1590 / 2175-623645774$

França, C. L. (2014). Aposentadoria: Crise ou liberdade? Em S. G. Murta, C. Leandro-França, \& J. Seidl, Programas de educação para aposentadoria: Como planejar, implementar e avaliar. Novo Hamburgo: Sinopsys.
Gonçalves, M. A., \& Vasconcellos, H. (1991). Consultoria. Revista Administração de Empresas, 31(2), 91-98. https://doi.org/10.1590/S0034-75901991000200010

Instituto Brasileiro de Geografia e Estatística - IBGE. (2013). Sintese de indicadores sociais: uma análise das condições de vida da população brasileira. Recuperado de http://biblioteca.ibge.gov.br/visualizacao/livros/liv66777.pdf

Kreling, N. H. (2016). Envelhecimento e inserção do idoso no mercado de trabalho, trabalho na Região Metropolitana de Porto Alegre. Indicadores Econômicos, 43(3), 141-154. Recuperado de https://revistas.fee.tche.br/index.php/ indicadores/article/view/3666

Leandro-França, C., Santos, J., \& Pedralho, M. (2015). Planejamento para aposentadoria: relato de intervenção em um grupo de homens de meia-idade. In S. G. Murta, C. Leandro-França, K. B. dos Santos, \& L. Polejack (Orgs), Prevenção e Promoção em Saúde Mental: Fundamentos, planejamento e estratégias de intervenção (pp. 823-843). Novo Hamburgo: Sinopsys.

Manzini, E. J. (2012). Uso da entrevista em dissertações e teses produzidas em um programa de pós graduação em educação. Revista Percurso - NEMO, 4(2), 149-171. Recuperado de https://repositorio.unesp.br/hand$\underline{\text { le } / 11449 / 114753}$

Martins, M. S., \& Massarollo, M. C. K. B. (2010). Conhecimento de idosos sobre seus direitos. ACTA, 23(4), 479-485. https://doi.org/10.1590/S010321002010000400006

Miranda, G. M. D., Mendes, A. C. G., \& Silva A. L. A. (2016). O envelhecimento populacional brasileiro: desafios e consequências sociais atuais e futuras. Revista Brasileira de Geriatria e Gerontologia, 19(3), 507-519. https://doi.org/10.1590/1809-98232016019.1501

Murad, I. (2017). O mercado de trabalho na área de administração. Revista Foco, 10(2), 82-97. Recuperado de http://revistafocoadm.org/index.php/foco/ article/view/421

Neves, D. R., Nascimento, R. P., Felix Jr., M. S., Silva, F. A., \& Andrade, R. O. B. (2018). Sentido e significado do trabalho: uma análise dos artigos em periódicos associados à Scientific Periodicals Eletronic Library. Fundação Getulio Vargas Cadernos Escola Brasileira Administração Pública e Empresas CAD. EBAPE. BR, 16(2), 318-330. https://doi.org/10.1590/1679-395159388

Ribeiro, L. A., \& Santana, L. C. (2015). Qualidade de vida no trabalho: fator decisivo para o sucesso organizacional. Revista Iniciação Científica- RIC Cairu, 2(2), 75-96. Recuperado de https://www.cairu.br/riccairu/pdf/artigos/2/06 QUALIDADE VIDA TRABALHO.pdf

Ribeiro, P. C. C., Almada, D. S. Q., Souto, J. F., \& Lourenço, R. A. (2018) Permanência no mercado de trabalho e satisfação com a velhice. Ciência e Saúde Coletiva, 23(8), 2683-2692. https://doi.org/10.1590/1413$\underline{81232018238.20452016}$

Rovida, M. F. (2016). Trabalho e identidade social: implicações nas pesquisas de comunicações. Revista Alterjor, 13(1), 183-200. Recuperado de http://www. revistas.usp.br/alterjor/article/view/112141

Santos, A. L., \& Gimenez, D. M. (2015). Inserção dos jovens no mercado de trabalho. Estudos Avançados, 29(85), 153-168. https://doi.org/10.1590/ $\underline{\text { S0103- } 40142015008500011}$

Serviço Brasileiro de Apoio às Micro e Pequenas Empresas - SEBRAE (2010). Critérios e Conceitos para a Classificação de Empresas. Recuperado de http:// www.sebrae-sc.com.br/leis/default.asp?vcdtexto $=4154$

Silva Júnior, A. S., Santos, C. I., Feitosa, M. G. G., \& Vidal, R. M. C. S. (2012). Consultoria: um estudo sobre o papel do consultor na formação da estratégia organizacional. Revista Ibero-Americana da Estratégia, 11(1), 178-203. https://doi.org/10.5585/riae.v11i1.1751

Silva, D. R. (2013). As contribuições do modelo de consultoria interna de recursos humanos para o alinhamento entre as pessoas e a estratégia da empresa. Revista de Gestão do Unilasalle, 2(2), 169-185. Recuperado de https://revistas. unilasalle.edu.br/index.php/desenvolve/article/view/1198

Vanzella, E., Lima Neto, E. A., \& Silva, C. C. A. (2011). A terceira idade e o mercado de trabalho. Revista Brasileira de Ciências 14(4), 194-204. https://doi. org/10.4034/RBCS.2010.14.04.13

\section{Informações sobre os autores:}

\section{Lygia Zaia Morato}

Alameda Jasmin, 66, Cerquilho - SP, Brasil, CEP 18520-000.

E-mail: lygiazaiamorato@gmail.com

\section{Heloísa Gonçalves Ferreira}

E-mail: helogf@gmail.com 